\title{
PATOGENIA DA LEISHMANIOSE CUTÂNEA EXPERIMENTAL. A IMPORTÂNCIA DA NECROSE NA ELIMINAÇÃO DOS PARASITOS DAS LESÕES
}

\author{
Zilton A. Andrade, Steven G. Reed, Silene B. Roters e \\ Moysés Sadigursky
}

\begin{abstract}
Um estudo histopatológico e ultraestrutural das lesões da leishmaniose cutânea causada pela Leishmania mexicana amazonensis em duas cepas isogênicas de camundongo, uma susceptivel (Balb/c) e outra resistente $(A / J)$, demonstrou que os amastigotas ficavam bem preservados nos vacúolos parasitóforos dos macrófagos, igualmente em ambas as cepas. A reação de imunofluorescência revelou antigenos parasitários no interior e na membrana dos macrófagos de maneira idêntica para ambas as cepas. $A$ diferença ocorria quando os macrófagos apareciam destruidos e as leishmanias ficavam livres ou fagocitadas por polimorfonucleares, neutrófilos e eosinófilos. Estes parasitos exibiam então graus variáveis de nitidas alteraçōes degenerativas. No camundongo resistence, a necrose, de tipo caseoso ou fibrinóide, era mais disseminada e mais frequente que no animal susceptivel. Os achados observados indicaram que as leishmanias não são destruidas no interior dos macrófagos e sim fora deles, especialmente quando fagocitadas por leucócitos polimorfonucleares. A necrose apareceu como o mecanismo mais saliente através do qual o hospedeiro elimina os parasitos das lesões, sendo a mesma um aspecto importante da reação de hipersensibilidade tardia que ocorre nos animais resistentes.
\end{abstract}

Palavras chaves: Leishmaniose cutânea experimental. Camundongos Balb/c e A/J. Leishmania mexicana amazonensis. Necrose tissular fibrinóide. Necrose tissular caseosa. Necrose tissular purulenta.

A patogenia das doenças causadas por Leishmanias vem sendo ultimamente estudada sob vários ângulos. Sabe-se que fatores do parasito e do hospedeiro são decisivos para determinar a forma clínica da infecção 1821 . No que diz respeito à leishmaniose cutânea, as suas formas clinicas polares (a ulcerosa e a difusa), bem como os modelos experimentais em animais isogênicos, têm revelado que a resistência se correlaciona com uma imunidade celular que se expressa por uma reação de hipersensibilidade tardia aos antigenos do parasito, enquanto a susceptibilidade se correlaciona com a imunodepressão celular e ativação policlonal humoral15 18 . Todavia, o mecarismo íntimo como se processa a destruição dos parasitos ainda não está bem compreendido. Como as leishmanias vivem no interior dos macrófagos e estes últimos são elementos de primeira linha na defesa contra as infecções, há nos vários estudos um pressuposto arraigado de que os macrófagos fagocitam as

\footnotetext{
Centro de Pesquisas Gonçalo Moniz (FIOCRUZ/UFBA) Salvador, Bahia, com apoio dos Institutos Nacionais de Saude, USA (Grant no 16282) e da FINEP (Convênio 43.82.0094.00).
}

Recebido para publicação em 30/7/1984. leishmanias para destrui-las e quando não o fazem é porque estão deficientes 91315 ou não receberam o estímulo apropriado dos linfócitos $\mathrm{T}^{6}$. Recentemente, estudamos a imunopatologia da leishmaniose cutânea experimental causada pela Leishmania mexicana amazonensis, em camundongos susceptiveis (Balb/c) e em camundongos relativamente resistentes $(A / J)$, e verificamos que o maior grau de destruição das leishmanias ocorria não no interior dos macrófagos, mas fora deles ${ }^{2}$. Como tal aspecto nos pareceu de importância para o entendimento da imunopatologia da leishmaniose, resolvemos estender o estudo inicial, explorando mais minuciosamente os aspectos ultraestruturais e imunopatológicos das lesões determinadas pela $L$. mexicana amazonensis nos animais susceptiveis e resistentes:

\section{MATERIAL E MÉTODOS}

Foram utilizados camundongos isogênicos $\mathrm{Balb} / \mathrm{c}$ e A/J de 6 a 8 semanas de idade. A inoculação da $L$. mexicana amazonensis foi feita no coxim da pata traseira direita e o inóculo contido em $0,025 \mathrm{ml}$ era representado por aproximadamente $1,5 \times 10^{7}$ promastigotas de cultura. Os detalhes sobre a pesquisa de anticorpos especificos, o teste cutâneo de hiper- 
sensibilidade retardada, bem como a caracterização da amostra dos parasitos aparecem em nosso trabalho anterior ${ }^{2}$. Apenas dados adicionais serão mencionados aqui. Foi acrescentado agora o estudo de animais com 3 meses de infecção, tempo em que a infecção no camundongo Balb/c se generalizou, aparecendo nódulos múltiplos na cauda, orelhas, patas e focinho. No animal $\mathbf{A} / \mathbf{J}$ a lesão inicial na pata permaneceu como um pequeno nódulo esbranquiçado e duro.

Para o estudo de imunofluorescência foi utilizado um anti-soro especifico contra $L$. mexicana amazonensis produzido em coelhos e gentilmente cedido pelo Dr. John David, Universidade de Harvard, Boston, USA. Como controle foi utilizado soro dos mesmos coelhos mencionados acima e obtido antes da imunização. Os tecidos moles da pata dos camundongos $\mathrm{A} / \mathrm{J}$ e $\mathrm{Balb} / \mathrm{c}$ foram retirados após 1 e 2 meses da infecção. Estes tecidos foram rapidamente congelados a $-196^{\circ} \mathrm{C}$ em nitrogênio liquido e depois cortados em criótomo mantido à temperatura de $-20^{\circ} \mathrm{C}$. O anti-soro especifico foi usado nas diluiçōes 1:2, 1:5 e 1:10. Para a reação de imunofluorescência indireta foi usado o anti-IgG de coelho conjugado com isotiocianato de fluoresceina e diluído a 1:40. Após o tratamento das secções com os soros respectivos e lavagens intermediárias em salina tamponada, as seç̧ōes foram montadas em glicerina e examinadas em microscópio Zeiss de fluorescência dentro de 24 horas.

Para a microscopia eletrônica os fragmentos de tecidos representativos da infeç̧ão de 1 e 2 meses, nas duas cepas de camundongos, sofreram dupla fixação em gluteraldeído e ácido ósmico e foram incluidos na resina de Spurr. As secções semifinas (1 micrômetro de espessura) ofereceram excelente material para estudo e foram analisadas ao microscópio ótico após coloração com azul de toluidina. Os cortes ultrafinos foram contrastados com acetato de uranila a $1 \%$ seguido do citrato de chumbo e foram examinados em um microscópio Zeiss EM-109 com 50mv.

Para a microscopia de luz os tecidos foram fixados em líquido de Bouin. Quando o material incluia o tecido ósseo da pata, a fixação foi feita em formol a $10 \%$ e a descalcificação processada por intermédio do EDTA. O material incluído em parafina teve as secções de 5 micrômetros de espessura coradas em hematoxilina eosina, tricrômico de Masson, reticulina de Gomori e pelo método do ácido periódico de Schiff (PAS).

\section{RESULTADOS}

A lesão produzida pela inoculação na pata do camundongo $\mathrm{Balb} / \mathrm{c}$ cresceu progressivamente, atingindo aos 2 e 3 meses até $1,4 \mathrm{~cm}$ no maior diâmetro, enquanto no $\mathrm{A} / \mathrm{J}$ o maior diâmetro não ultrapassou $0,32 \mathrm{~cm}$. Os niveis de anticorpos IgG determinados por imunofluorescência permaneceram igualmente elevados em ambas as cepas de camundongos. A reação cutânea tardia ao antígeno de leishmania injetado intradermicamente foi se tornando progressivamente mais fraca no $\mathrm{Balb} / \mathrm{c}$ ate ser totalmente negativa aos 2-3 meses. Ao contrário, no $\mathrm{A} / \mathrm{J}$ tal reação foi se tornando cada vez mais nitida com o passar do tempo. As alterações histológicas foram distintas nas duas cepas, sendo no Balb/c constituida por extensas coleções de macrófagos vacuolados e parasitados, formando uma reação monomórfica, por vezes simulando histologicamente o tecido adiposo (Figura 1). Já no A/J havia uma reação celular mista, com muitos linfócitos, fibroblastos, macrófagos parasitados ou não, alguns plasmócitos e muitos leucocitos polimorfonucleares neutrófilos e eosinófilos (Figura 2). Com o passar do tempo a lesão no Balb/c se estendia e as células parasitadas apareciam entre as fibras musculares estriadas, se insinuavam entre as fibras colágenas dos tendões e invadiam a medula óssea e o linfonodo popliteo iso-lateral, sendo que, mais tarde no curso da infecção, as coleções nodulares de macrófagos parasitados apareciam em vários sítios metastáticos cutâneos. A visceralização para baço e figado foi demonstrada em cultura, mas não histologicamente. No camundongo $A / J$ a lesão permaneceu sempre localizada, o seu tamanho se reduziu com o tempo e as alterações histológicas evoluíram progressivamente para a fibrose, especialmente na periferia do nódulo inflamatório. $\mathrm{O}$ número de parasitos aparentemente diminuiu com o passar do tempo, mas as leishmanias foram sempre encontradas facilmente nas secções histológicas até o fim da observação ( 3 meses), seja no tecido intersticial, seja no interior de macrófagos vacuolados, (Figura 3).

A necrose foi um achado proeminente e constante nas lesões nas duas cepas de camundongos. No Balb/c ela era de aparecimento mais tardio e se caracterizava por ser multifocal, coagulativa, e freqüentemente invadida por leucócitos polimorfonucleares (necrose purulenta). No $\mathrm{A} / \mathrm{J}$ a necrose aparecia em focos microscópicos, numerosos, mas isolados e freqüentemente assumia o tipo fibrinóide. Nas lesões mais iniciais os focos necróticos podiam aparecer invadidos por leucócitos polimorfonucleares e formavam microabcessos esparsos (Figura 4). A microscopia ótica de alta resolução feita em cortes semifinos fornecem 
Andrade ZA, Reed SG, Roters SB, Sadigursky M. Patogenia da leishmaniose cutânea experimental. Revista da Sociedade Brasileira de Medicina Tropical 17:187-197, Out-Dez, 1984

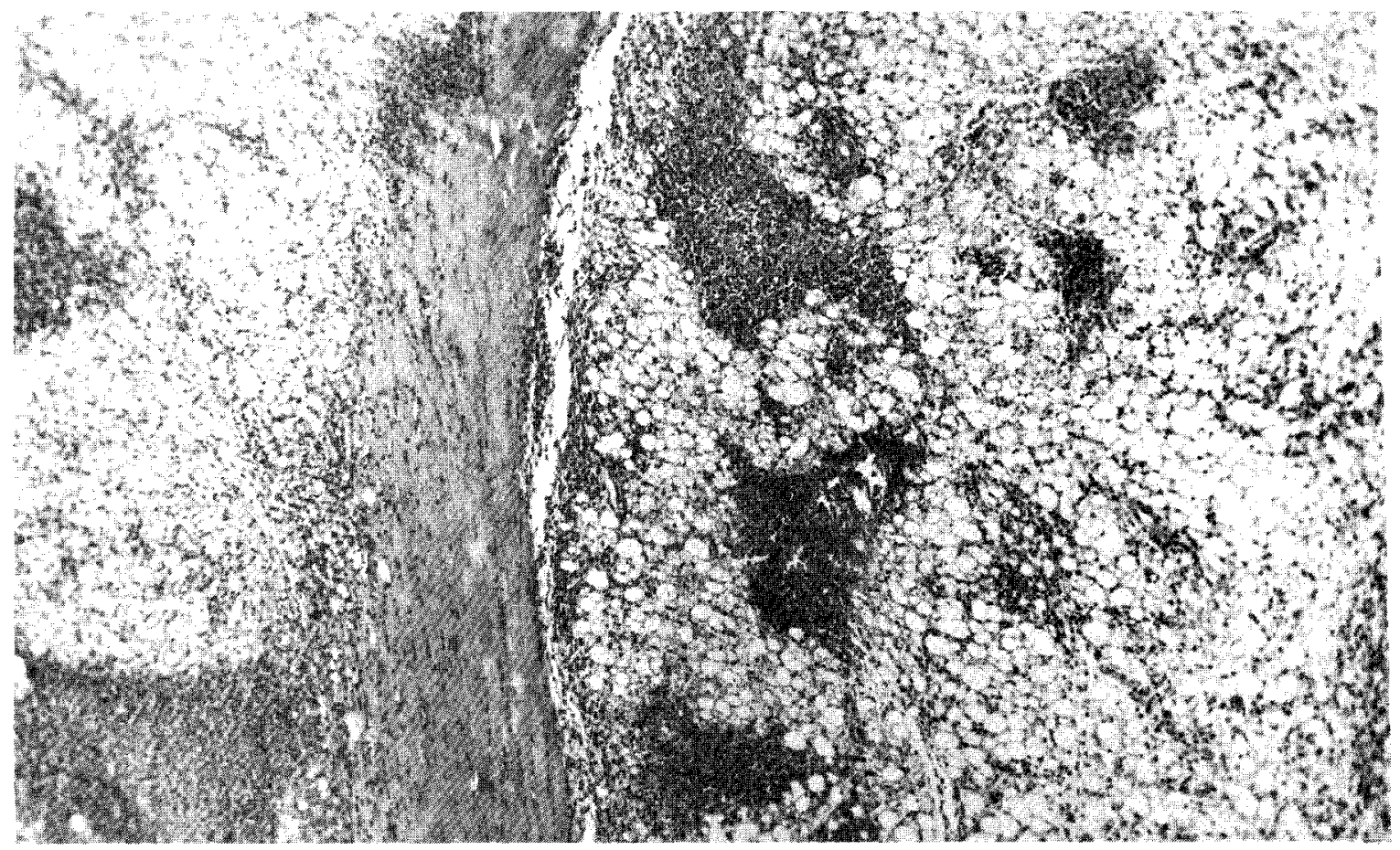

Fig. I - Lesão avançada ( 2 meses) causada pela $L$. mexicana amazonensis na pata do camundongo Balb/c. A coleção de macrófagos parasitados e vacuolados dá o aspecto de um tecido adiposo. As áreas escuras representam focos de necrose purulenta. Vê-se a estrutura de um tecido conjuntivo denso (tendão) sendo invadida por células parasitadas. (Hematoxilina e Eosina, X80).

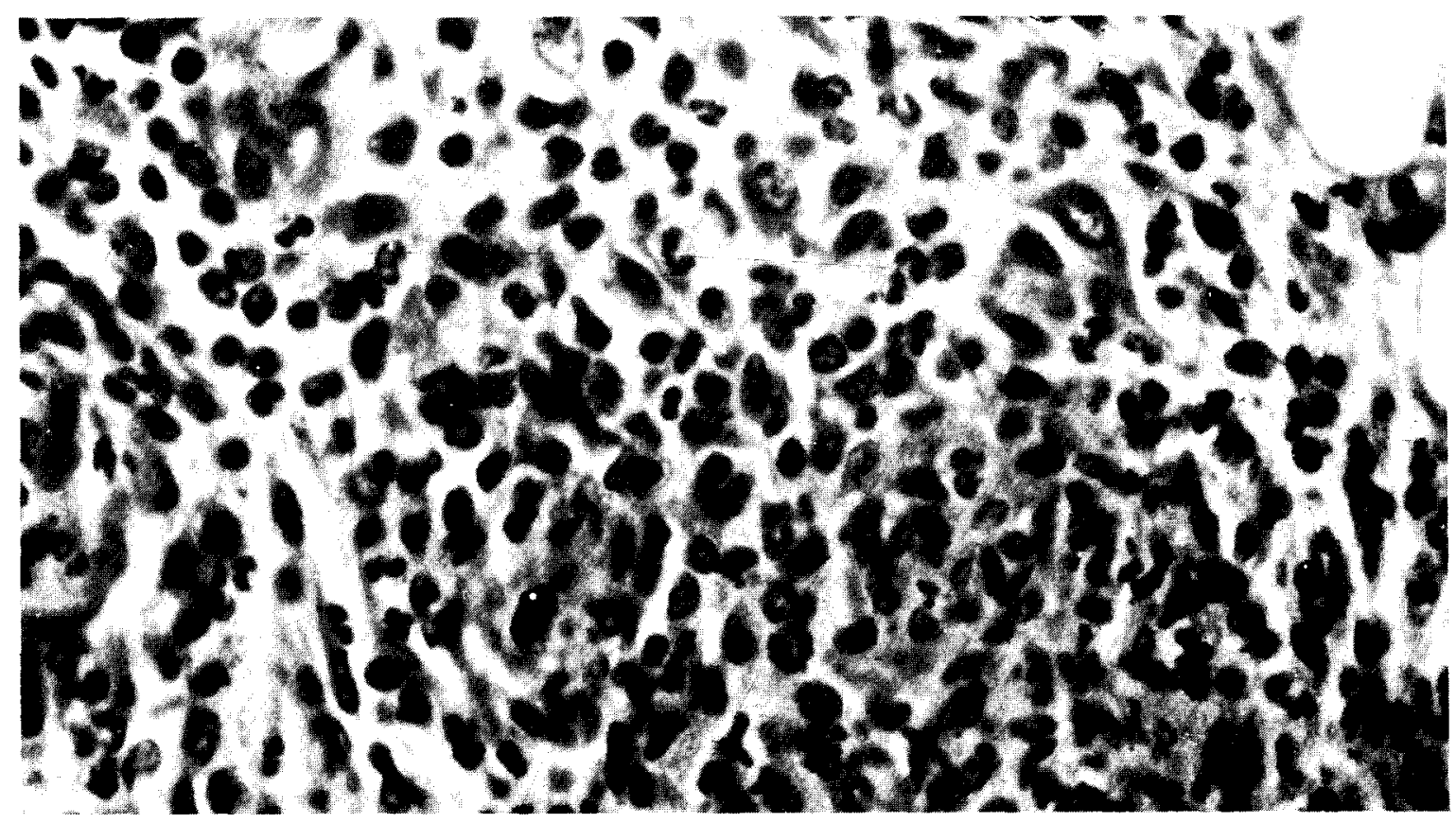

Fig. 2 - Tipica reação celular mista produzida no camundongo A/J pela $L$. mexicana amazonensis. Os leucócitos polimorfonucleares aparecem de mistura com macrófagos, fibroblastos e linfócitos. Os parasitos não são evidentes nesta área. (Hematoxilina-Eosina X400). 
Andrade ZA, Reed SG, Roters SB, Sadigursky M. Patogenia da leishmaniose cutânea experimental. Revista da Sociedade Brasileira de Medicina Tropical 17:187-197, Out-Dez, 1984

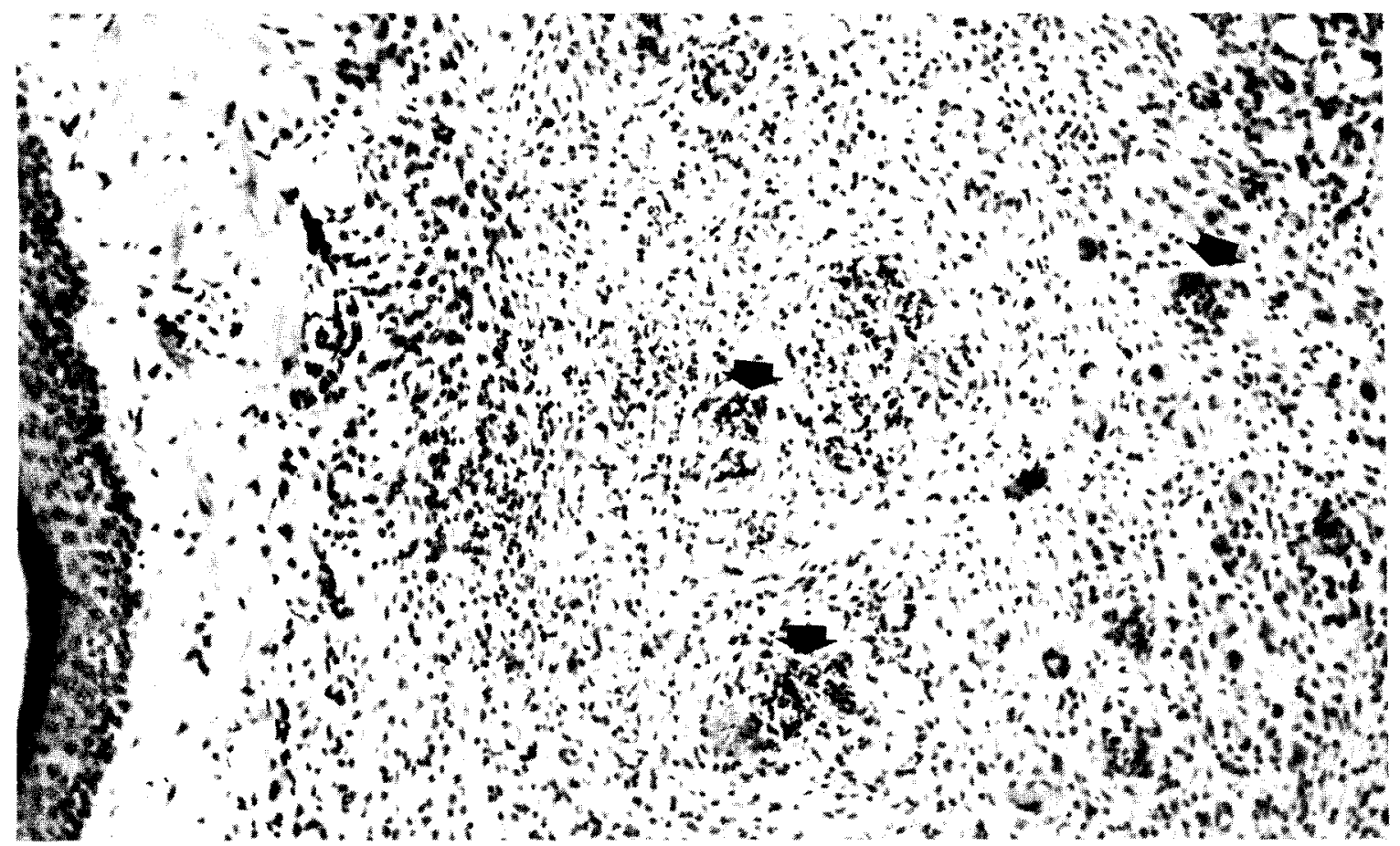

Fig. 3 - Lesào observada após 2 meses de infecçāo no camunđongo A/J. Ha reaçao ceıuıar mısta, com muitos linfócitos e já com formação de tecido fibroso, mas os macrófagos parasitados e vacuolados continuam presentes (setas). (Hematoxilina e Eosina, $\mathrm{X} 300$ ).

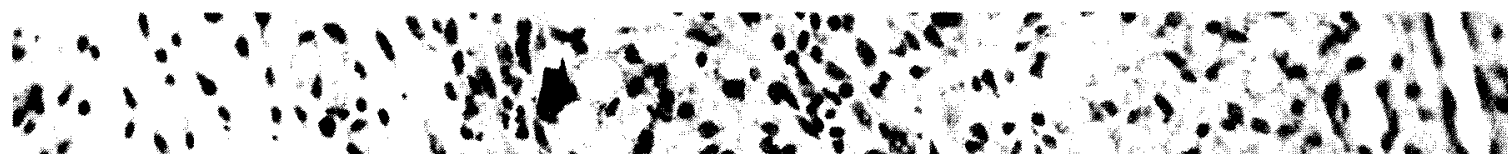

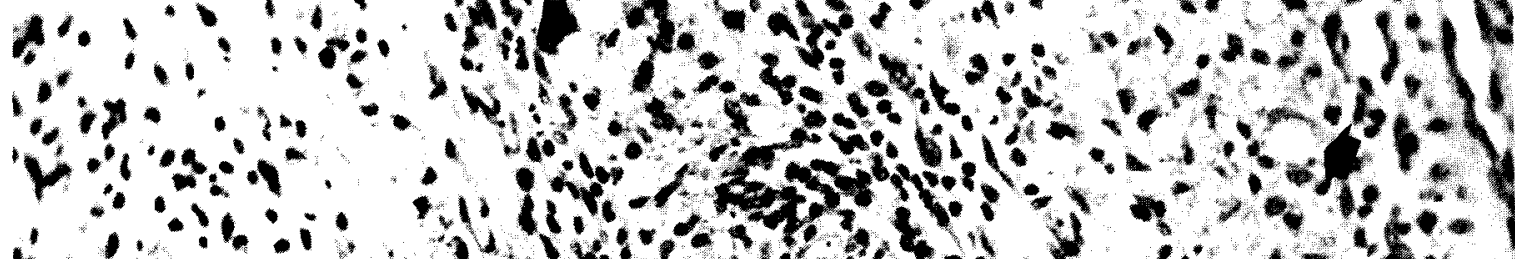
How H.

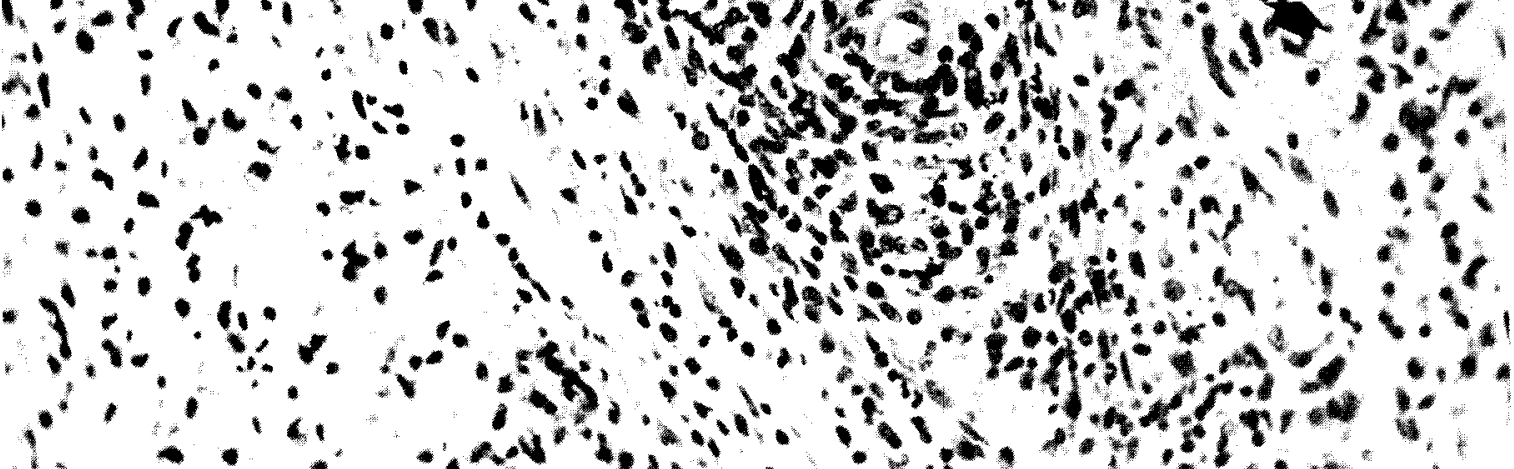

Fig. 4 - Lesão inicial (duas semanas) no camundongo A/J. Vê-se bem a lesão inflamatória crônica inespecífica no derma profundo e a presença de vários microabcessos (setas). (Hematoxilina e Eosina X100). 


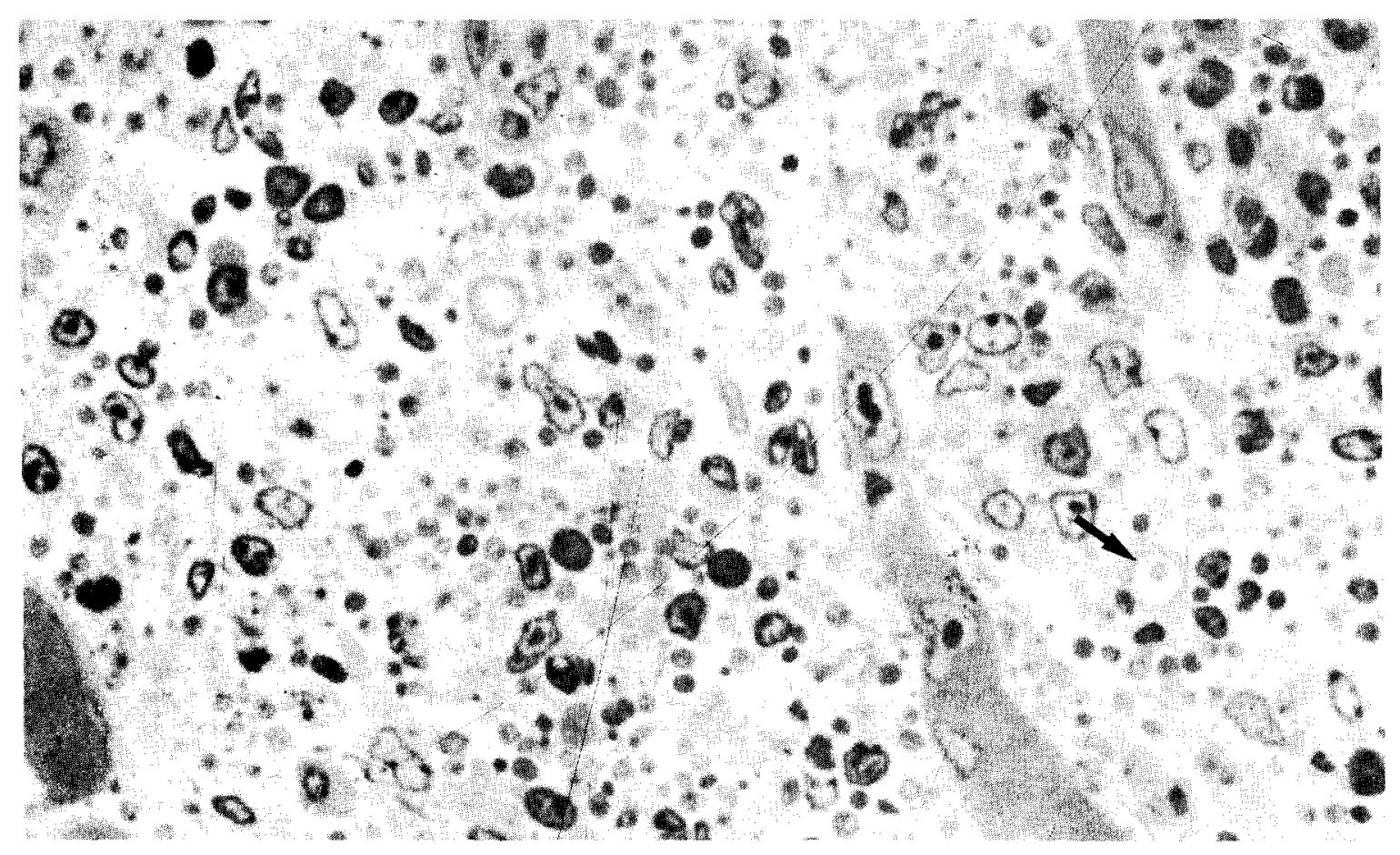

Fig. 6 - Leishmaniose do camundongo A/J. Aspecto comumente observado em que os amastigotas aparecem em grande numero, mas fora das células e muitos elementos celulares aparecem destruídos. Apenas um pequeno vacúolo parasitóforo pode ser notado (seta). (Corte de 1 micrômetro de espessura, corado pelo azul de toluidina, imersão, X1000).
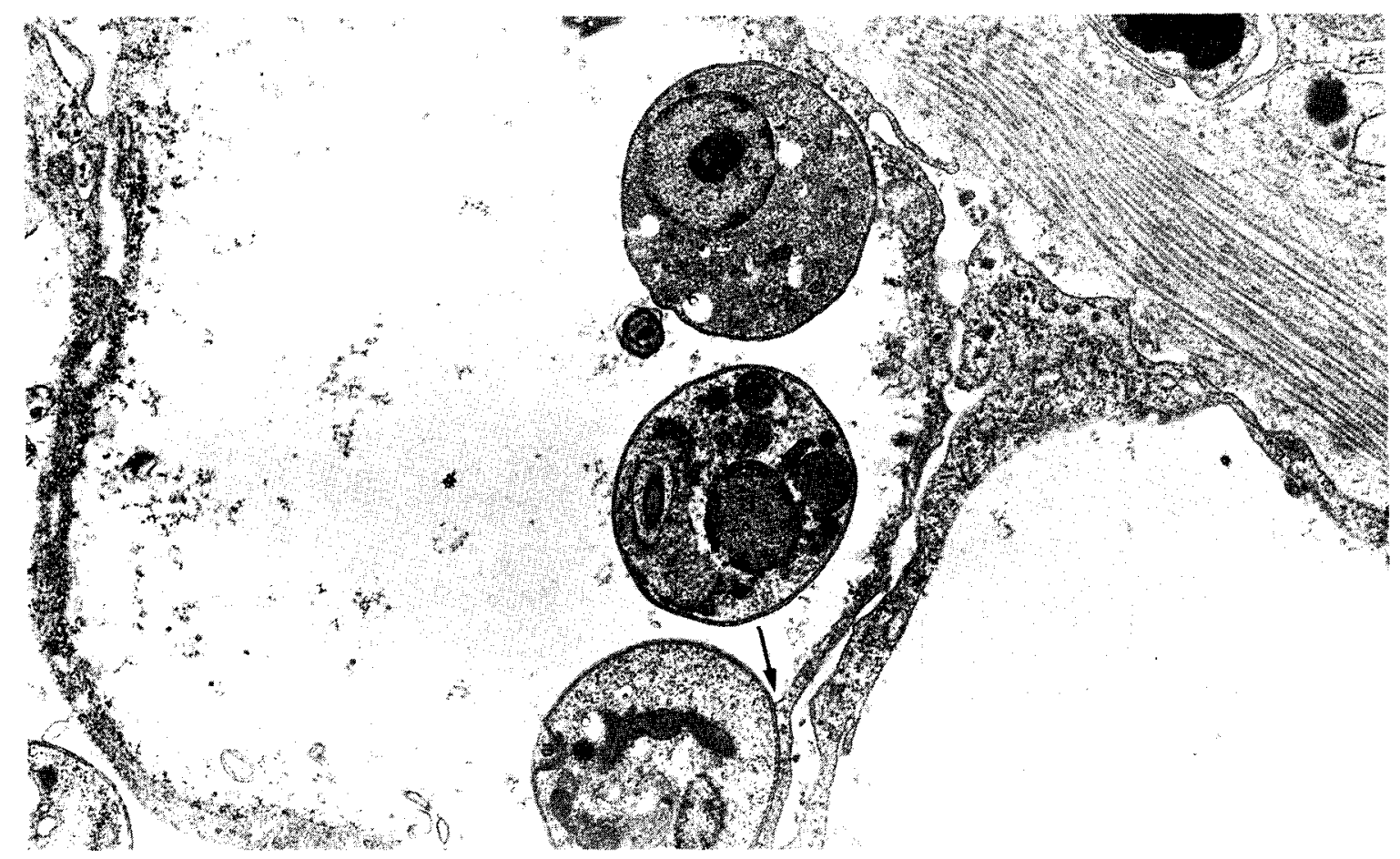

Fig. 7 - Vacúolo parasitóforo contendo leishmanias bem preservadas, uma das quais (setas) formando uma estreita junção com a parede do vacúolo. Balb/c, 1 mès de infecção. (X3000). 


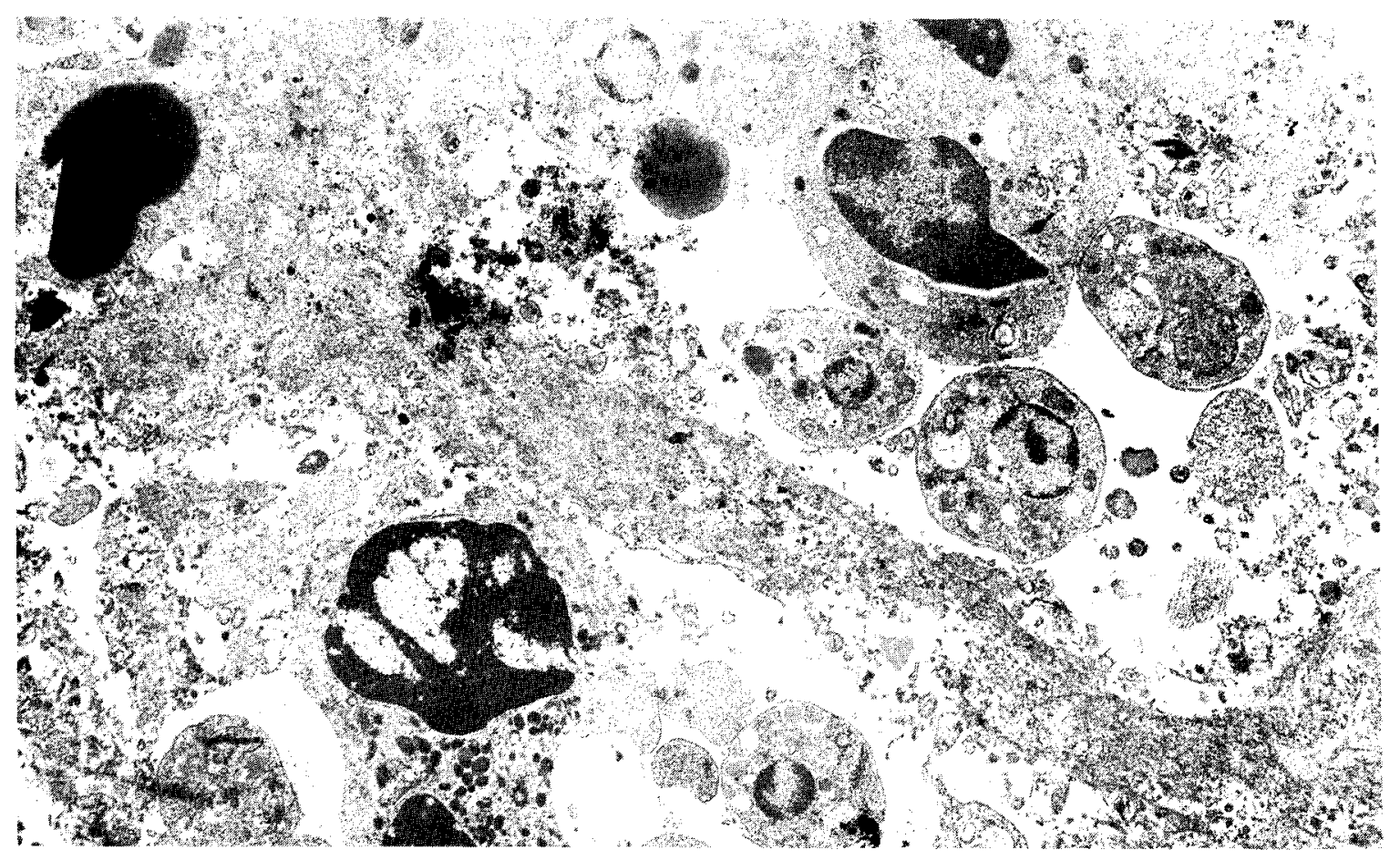

Fig. 8 - Micrografia eletrónica mostrando células em desintegração e amastigotas livres. Estes exibem vacuolizaçào, corpos lipídicos, enrugamento da membrana externa e densificação citoplasmática. A/J, 1 mês de infecção. (X3000).

entre as lesões das duas cepas de camundongos (Figura 12). Foi feita uma tentativa para se detectar fluorescência especifica ao nivel das membranas externas dos macrófagos. Este exame foi dificultado pela fluorescência não especifica (nervos, colágeno) do derma e pela autofluorescência de pigmentos (lipofuscina) e fibras elásticas presentes nos macrófagos e no intersticio. Todavia foi possivel se detectar a presença de fluorescência especifica nas membranas de alguns macrófagos tanto da cepa $\mathrm{Balb} / \mathrm{c}$ como $\mathrm{A} / \mathrm{J}$.

\section{DISCUSSÃO}

O macrófago, uma célula especialmente adaptada para a fagocitose e digestão intracelular de microorganismos, é todavia o habitat adequado para leishmanias, que não só permanecem vivas no seu interior, como aí crescem e se multiplicam. Já foi demonstrado que os lisossomos se fusionam com a membrana do vacúolo parasitóforo e assim derramam o seu conteúdo, mas este material aparentemente não interfere com os parasitos 14 14. Pouco se sabe sobre a ação do outro mecanismo destrutivo dos macrófagos, através dos radicais livres derivados de metabolitos do oxigènio, sobre as leishmanias intracelulares, mas há indicios de que este também estaria inibido 78 . Nacy e cols ${ }^{17}$, trabalhando com macrófagos peritoneais invitro e $L$. tropica verificaram que a adição de linfocinas à cultura tornava os macrófagos mais resistentes à infecçāo, pois estes inibiam o crescimento das leishmanias e provocavam a sua destruição e dissolução. No nosso material não conseguimos obter evidências de que as leishmanias aparecem mais lesadas nos macrófagos dos animais resistentes (com boa resposta cutânea retardada dos antigenos das leishmanias) em oposição ao que acontece com os animais susceptiveis. Embora as células parasitadas do camundongo resistente $(\mathrm{A} / \mathrm{J})$ aparecessem menos distendidas e com menor número de leishmanias nos vacúolos parasitóforos, não se detectou maior grau de lesões degenerativas nos amastigotas localizados no seu interior em comparação com o que acontecia no animal susceptivel (Balb/c). $\dot{\mathrm{E}}$ possivel que as espécies de leishmanias tenham comportamento diferente. Haidaris e Bonventre ${ }^{12}$ demonstraram que os macrófagos ativados por várias maneiras ( $M$. tuberculosis, $C$. parvum) exibiram uma intensa atividade tumoricida, mas tal não correu paralelo com a capacidade de destruir a $L$. donovani. Esta capacidade só apareceu com a adição continuada de linfocinas por vários dias após a infecção das células. Nos estudos in vitro é possivel que vários fatores, tais como a origem dos macrófagos, o tipo de 
Andrade ZA, Reed SG, Roters SB, Sadigursky M. Patogenia da leishmaniose cutânea experimental. Revista da Sociedade Brasileira de Medicina Tropical 17:187-197, Out-Dez, 1984



Fig. 9 - Leucócito polimorfonuclear neutrofilo fagocitando várias leishmanias, as quais exibem acentuadas alterações degenerativas e necróticas. Em torno há células em desintegração e algumas leishmanias melhor preservadas ainda são vistas no interior de vacúolos parasitóforos. A/J, 1 mês de infecção (X3000).

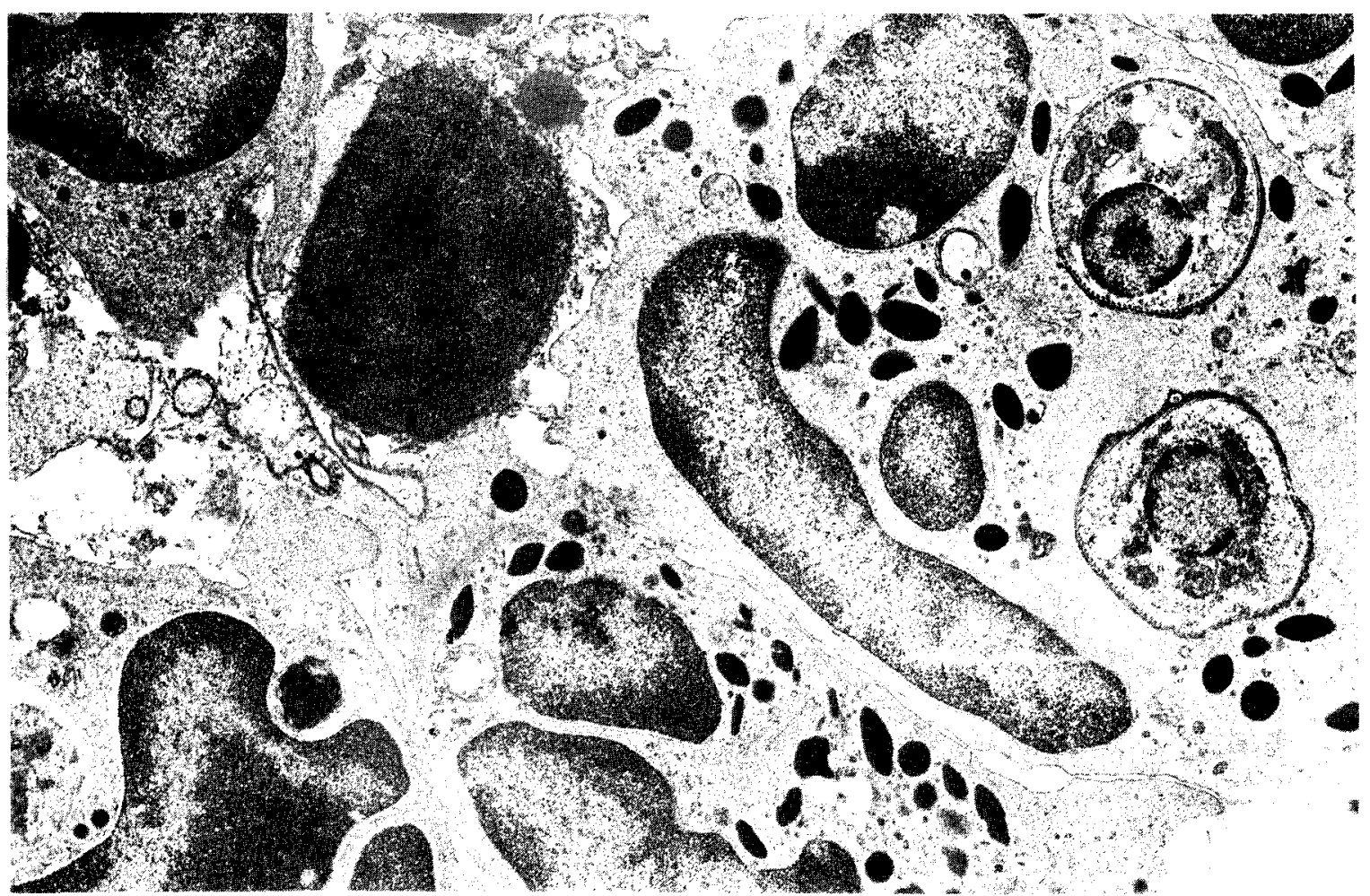

Fig. 10 - Leishmanias razoavelmente preservadas, mas já nítidas alteraçōes degenerativas (vacuolizaçao, enrugamento) são vistas no interior de um lleucócito polimorfonuclear eosinófilo. A/J, 2 meses de infecção (X3000). 
Andrade ZA, Reed SG, Roters SB, Sadigursky M. Patogenia da leishmaniose cutânea experimental. Revista da Soriedade Brasileira de Medicina Tropical 17:187-197, Out-Dez, 1984

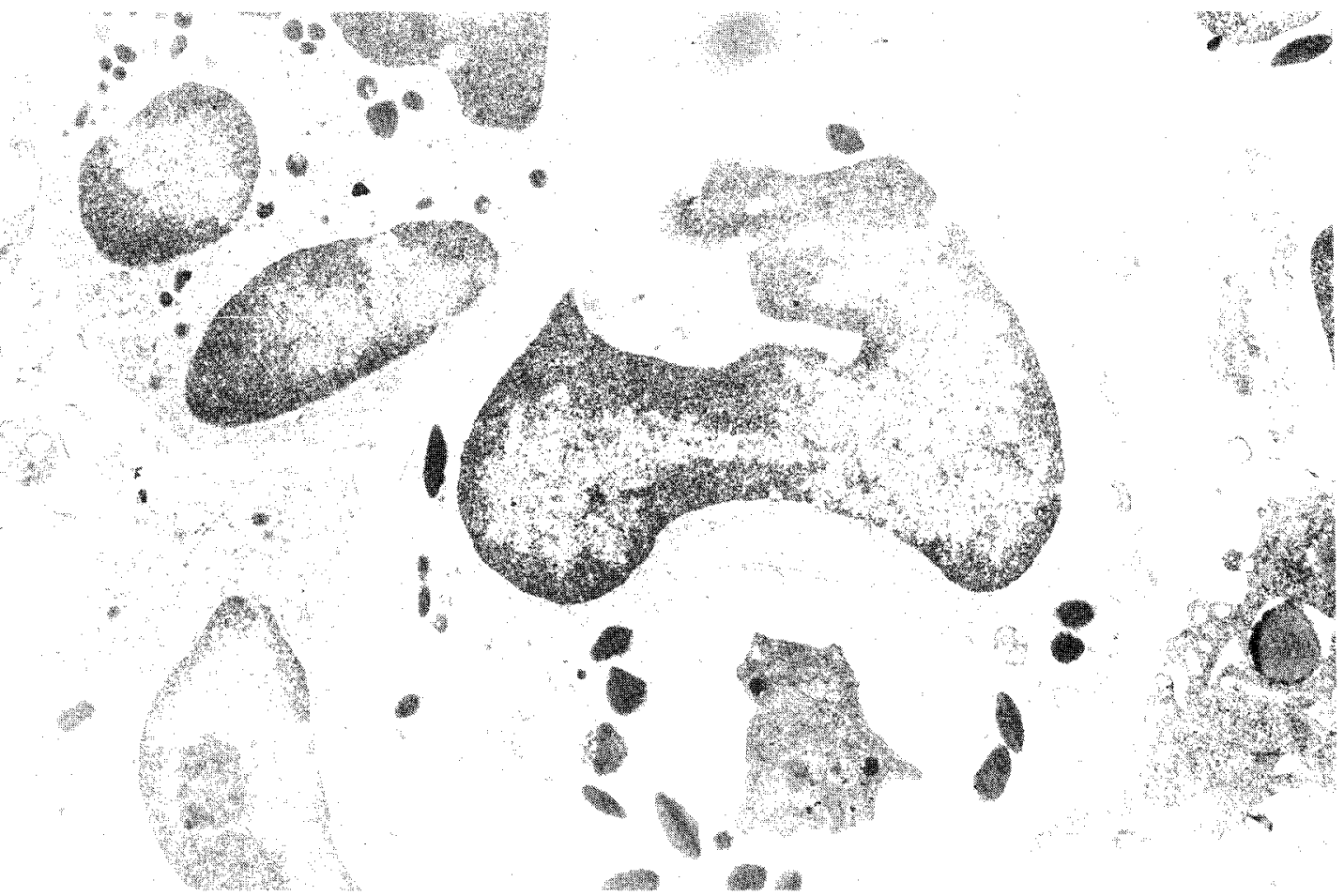

Fig. 11 - Leishmania já em fase avançada de desintegração aparece no interior de um vacúolo digestivo de um leucocito eosinófilo. A/J, 1 mês de infecçāo (X4500).

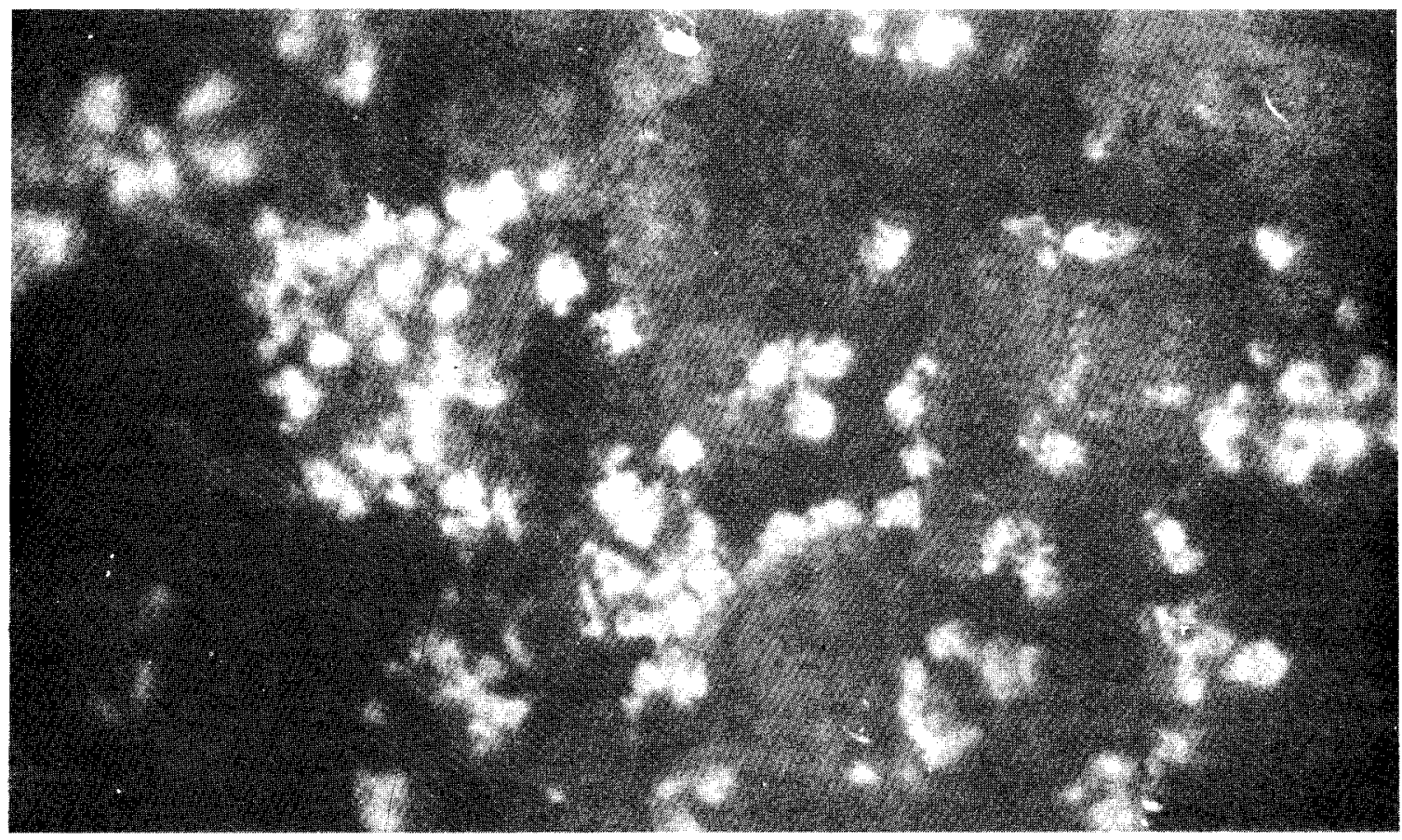

Fig. 12 - As numerosas leishmanias no interior de macrófagos aparecem com forte fluorescência, a qual é vista também no corpo e membrana externa dos macrófagos. Corte em criostato de lesão de 2 meses de duração no camundongo Balb/c. Anti-IgG especifica para L. mexicana (1:10) contracorada com anti-IgG de coelho fluoresceinada (1:40) (X 120). 
Andrade ZA, Reed SG, Roters SB, Sadigursky M. Patogenia da leishmaniose cutânea experimental. Revista da Sociedade Brasileira de Medicina Tropical 17:187-197, Out-Dez, 1984

leishmanias e o tipo das linfocinas produzidas sejam importantes, Scott e cols ${ }^{20}$ verificaram que os macrófagos estimulados por linfocinas foram capazes de destruir a $L$. tropica, mas não a cepa Maria da $L$. mexicana. É tambem possivel que a situação in vivo seja ainda mais complexa. Todavia acreditamos que os achados do presente estudo sugerem um fator que, pelo menos nas condições experimentais consideradas, parece ter fundamental importància na patogenia da leishmaniose cutànea. Este mecanismo se faz através da destruiçào especifica dos macrófagos parasitados ou da necrose multifocal dos tecidos parasitados com a conseqüente liberação das leishmanias. Os linfócitos $\mathrm{T}$ sensibilizados seriam os elementos cruciais, não atuando necessariamente através de linfocinas estimuladoras da destruição parasitária intracelular pelos macrófagos, mas causando citotoxicidade ao reconhecer os antigenos parasitários. No animal susceptivel poderia haver uma falha do linfócito $\mathrm{T}$ em reconhecer o antigeno, ja que a imunofluorescência, confirmando dados anteriores ${ }^{3} 11$, demonstrou a presença do mesmo nas membranas dos macrófagos. Outra alternativa seria uma falha dos macrófagos em processar os antigenos parasitários de maneira a que estes ficassem aptos a sensibilizar os linfócitos $\mathrm{T}^{13}$. As leishmanias liberadas poderiam sofrer a ação de anticorpos $1121 \mathrm{e} /$ ou serem fagocitadas por vários tipos celulares. Em um trabalho pioneiro Deane e Guimarães ${ }^{10}$ verificaram atraves do exame de esfregaços de sangue periférico provenientes de portadores de calazar e corados pelo May-Grünwald-Giemsa que os polimorfonucleares neutrófilos e eosinófilos fagocitavam e destruíram as leishmanias, enquanto que nos macrófagos estas se multiplicavam e apenas raramente apresentavam alteraçōes degenerativas. Fazendo estudos in vitro com a $L$. mexicana, Chang ${ }^{7}$ demonstrou que as leishmanias se mantiveram bem nos macrofagos, mas não nos polimorfonucleares. As reações para os metabolitos do oxigênio e peroxidase foram positivas em todos os tipos celulares parasitados, mas os parasitos apresentaram alterações degenerativas apenas no interior dos polimorfonucleares neutrófilos e eosinófilos. Ele acha que as leishmanias são lesadas por um sistema microbicida formado por mieloperoxidase $\mathrm{H}_{2}$ O-halida, sendo que a opsonização não è necessária para qualquer dos fagócitos. Os nossos achados in vivo confirmam plenamente o que foi visto in vitro, ao mostrar indícios de destruição dos amastigotas quando fagocitados por polimorfonucleares neutrofilos e eosinófilos, ou quando situados extracelularmente.

A necrose dos tecidos parasitados já foi identificada como um mecanismo de defesa. Bryceson e cols 5 verificaram que linfócitos sensibilizados destruíam as monocamadas de macrófagos parasitados pela $L$. enrietti. É interessante notar que a lesão por esta leishmania no cobaio evolui até cerca de 4 semanas com o aspecto "virchowiano", quando então sofre infiltração linfocitária, seguida de necrose, regressão e fibrose ${ }^{16}$.

Ridley ${ }^{19}$ considera a necrose como um indicador histologico de resistência. Ele encontrou os mais baixos indices de parasitismo em lesões humanas quando a necrose estava presente e verificou correlaçào entre a presença de necrose e células plasmáticas nos casos da Etiópia e entre necrose e linfócitos nos casos do Brasil.

Nos nossos animais a necrose apareceu tanto na infecçào do Balb/c como na do $\mathrm{A} / \mathrm{J}$. Na primeira era de tipo coagulativo, provavelmente isquêmica, e logo sofria densa invasão de polimorfonucleares neutrófilos, mas sem alterações outras do resto do quadro histológico fundamental e monomórfico. No camundongo $\mathrm{A} / \mathrm{J}$ a necrose era de tipo caseosa ou fibrinóide, aparecia em focos microscópicos e era logo substituída por tecido fibroso. Ela era muito freqüente e, nas preparaçōes examinadas ao microscópio eletrônico, estava sempre presente, seja como necrose de grupos celulares, seja como necrose de macrófagos isolados. Portanto, ao lado das alterações outras sugestivas da presença de um mecanismo de hipersensibilidade celular, tais como a reação vásculo-necrótica, a reação invasivo-destrutiva, a reação fibrosante, a reação granulomatosa, a necrose, caseosa ou fibrinóide, merece ser considerada como importante indicador de resistência na leishmaniose cutânea.

\section{SUMMARY}

Amastigotes of Leshmania mexicana amazonensis appeared healthy and well preserved within the parasitophorous vacuoles of macrophages during the infection of a susceptible $(B a l b / c)$ or a relatively resistant $(A / J)$ inbred strain of mice. Immunofluorescence showed the presence of leishmanial antigens within infected macrophages and in their external membranes similar for both strains. When the amastigotes were found extracellularly or within polymorphonuclear neutrophils or eosinophils, marked ultrastructural degenerative changes were observed in them. Such necrotic alterations were seen frequently in the resistant mice and rarely in the susceptible ones. Thus, necrosis of parasitized macrophages appeared as a major mechanism through which the resistant host eliminates the parasites from the lesions. It may be considered as a histological 
Andrade ZA, Reed SG. Roters SB, Sadigursky M. Patogenia da leishmaniose cutânea experimental. Revista da Sociedade Brasileira de Medicina Tropical 17:187-197, Out-Dez, 1984

marker of resistance in leishmaniasis and represents a prominent component of the delayed-type immunological mechanism occurring in resistant hosts.

Key words: Experimental cutaneous leishmaniasis. Balb/c and $A / J$ mice. Leishmania mexicana amazonensis Fibrinoid tissue necrosis. Caseous tissue necrosis. Purulent tissue necrosis.

\section{REFERÊNCIAS BIBLIOGRÁFICAS}

1. Alexandre J, Vickerman K. Fusion of host cell secondary lysosomes with the parasitophorous vacuoles of Leishmania mexicana infected macrophages. Journal of Protozoology 22: 502-508, 1975.

2. Andrade ZA, Reed SG, Roters SB, Sadigursky M. Immunopathology of experimental cutaneous leishmaniasis. American Journal of Pathology 114:137-148, 1984.

3. Berman JDS, Dwyer DM. Expression of leishmania antigen on the surface membrane of infected human macrophages in vitro. Clinical and Experimental Immunology 44:342-348, 1981 .

4. Berman JDS, Dwyer DM, Wyler DJ. Multiplication of Leishmania in human macrophages in vitro. Infection and Immunity 26:375-379, 1979.

5. Bryceson ADM, Bray RS, Wolstencroft RA, Dumonde DC. Immunity in cutaneous leishmaniasis of guinea-pig. Clinical and Experimental Immunology 7:301-341, 1970.

6. Buchmüller YS, Manuel J. Studies on the mechanisms of macrophage activation. II. Parasite destruction in macrophages activated by supernates from Concanavalin A-stimulated lymphocytes. Journal of Experimental Medicine 150:359-370, 1979.

7. Chang PK. Leishmanicidal mechanisms of human polymorphonuclear phagocytes. American Journal of Tropical Medicine and Hygiene 30:322-333, 1981.

8. Chang PK, Chiao JW. Cellular immunity of mice to Leishmania donovani in vitro: lymphokine-mediated killing of intracellular parasites in macrophages. Proceedings of the National Academy of Sciences 78:70837087,1981 .

9. Chang PK, Dwyer DM. Multiplication of a human parasite (Leishmania donovani) in phagolysosomes of hamster macrophages in vitro. Science 193:678-680, 1976.
10. Deane L, Guimarães FN. Aspectos interessantes de phagocytose observados na leishmaniose visceral e na malária. Memórias do Instituto Oswaldo Cruz 33:263$279,1938$.

11. Farah FS, Samra SA, Nuwayri-Salti N. The role of macrophage in cutaneous leishmaniasis. Immunology 29:755-764, 1975.

2. Haidaris CG, Bonventre PF. Elimination of Leishmania donovani amastigotes by activated macrophages. Infection and Immunity 33:918-926, 1981.

13. Howard JG, Hale C, Liew FY. Genetically determined response mechanisms to cutaneous leishmaniasis. Transactions of the Royal Society of Tropical Medicine and Hygiene 76:152-154, 1982.

14. Lewis DH, Peters W. The resistance of intracellular Leishmania parasites to digestion by lysosomal enzymes. Annals of Tropical Medicine and Parasitology 71:295$312,1977$.

15. Mauel J, Behin R. Immunology of leishmaniasis. In: Levanwsky M, Hutner SH, (ed) Biochemistry and physiology of Protozoa $2^{\text {nd }}$ edition, vol. 4 p. 385-429, Academic Press, New York, 1981.

16. Monroy A, Ridley DS, Heather CJ, Ridley MJ. Histological studies on the elimination of Leishmania enrietti from skin lesions in the guinea-pig. British Journal of Experimental Pathology 61:601-610, 1980.

17. Nacy CA, Meltzer MS, Leonard EJ, Wyler D. Intracellular replication and lymphokine-induced destruction of Leishmania tropica in $\mathrm{C}_{3} \mathrm{H} / \mathrm{HeN}$ mouse macrophages. Journal of Immunology 127:2381-2386, 1981.

18. Pérez $\mathrm{H}$. Factors influencing the host response to Leishmania mexicana. Cytopathology of parasitic diseases. Ciba Foundation Symposium 99: 157-173. Pitman Books, London, 1983.

19. Ridley DS. The pathogenesis of cutaneous leishmaniasis. Transactions of the Royal Society of Tropical Medicine and Hygiene 73: 150-160, 1979.

20. Scott P, Sacks D, Sher A. Resistance to macrophagemediated killing as a factor influencing the pathogenesis of chronic cutaneous leishmaniasis. Journal of Immunology 131:966-971, 1983 .

21. Sher A, Sacks DL, Scott PA. Host and parasite factors influencing the expression of cutaneous leishmaniasis. Cytopathology of parasitic disease. Ciba Foundation Symposium 99: 174-189. Pitman Books, London, 1983. 